\title{
Enzyme Inhibitory Properties, Antioxidant Activities, and Phytochemical Profile of Three Medicinal Plants from Turkey
}

\author{
Gokhan Zengin, ${ }^{1}$ Gokalp Ozmen Guler, ${ }^{2}$ Abdurrahman Aktumsek, ${ }^{1}$ Ramazan Ceylan, \\ Carene Marie Nancy Picot, ${ }^{3}$ and M. Fawzi Mahomoodally ${ }^{3}$ \\ ${ }^{1}$ Department of Biology, Science Faculty, Selçuk University Campus, 42250 Konya, Turkey \\ ${ }^{2}$ Department of Biological Education, Ahmet Keleşoğlu Education Faculty, Necmettin Erbakan University, 42090 Konya, Turkey \\ ${ }^{3}$ Department of Health Sciences, Faculty of Science, University of Mauritius, 230 Réduit, Mauritius
}

Correspondence should be addressed to Gokhan Zengin; gokhanzengin@selcuk.edu.tr and M. Fawzi Mahomoodally; f.mahomoodally@uom.ac.mu

Received 25 September 2015; Revised 25 November 2015; Accepted 26 November 2015

Academic Editor: Berend Olivier

Copyright (C) 2015 Gokhan Zengin et al. This is an open access article distributed under the Creative Commons Attribution License, which permits unrestricted use, distribution, and reproduction in any medium, provided the original work is properly cited.

\begin{abstract}
We aimed to investigate the inhibitory potential of three medicinal plants (Hedysarum varium, Onobrychis hypargyrea, and Vicia truncatula) from Turkey against key enzymes involved in human pathologies, namely, diabetes ( $\alpha$-amylase and $\alpha$-glucosidase), neurodegenerative disorders (tyrosinase, acetylcholinesterase, and butyrylcholinesterase), and hyperpigmentation (tyrosinase). The antioxidant potential, phenolic and flavonoid content of ethyl acetate, and methanolic and aqueous extracts were investigated using in vitro assays. The total antioxidant capacity (TAC), $\beta$-carotene/linoleic acid bleaching activity, 1,1-diphenyl-2-picrylhydrazyl free radical $\left(\mathrm{DPPH}^{*}\right), 2,2$-azino-bis(3-ethylbenzothiazoline-6-sulfonic acid) (ABTS ${ }^{*+}$ ), cupric ion reducing antioxidant capacity (CUPRAC), ferric reducing antioxidant power (FRAP), and metal chelating activity on ferrous ions were used to evaluate the antioxidant capabilities of the extracts. The half-maximal inhibitory concentrations $\left(\mathrm{IC}_{50}\right)$ of the extracts on cholinesterase, tyrosinase, and $\alpha$-amylase were significantly higher than the references, galantamine, kojic acid, and acarbose, respectively. The half-maximal effective concentrations $\left(\mathrm{EC}_{50}\right)$ of the extracts on TAC, CUPRAC, and FRAP were significantly higher than trolox. The phenol and flavonoid contents of the plant extracts were in the range $20.90 \pm 0.190-83.25 \pm 0.914 \mathrm{mg}$ gallic acid equivalent/g extract and $1.45 \pm 0.200-39.71 \pm 0.092 \mathrm{mg}$ rutin equivalent/g extract, respectively. The plants were found to possess moderate antioxidant capacities and interesting inhibitory action against key enzymes.
\end{abstract}

\section{Introduction}

Turkey has been described as one of the countries which has the richest floral biodiversity worldwide [1]. Indeed, this is due to its unique geographical location, climatic conditions, and geomorphological characteristics [2,3]. Approximately, 10,500 species have been identified in Turkey and 30\% were found to be endemic [2]. The relatively high rate of endemism in Turkey provides an indication of the richest biodiversity in this area [1].

Herbal medicinal systems, knowledge, and practices have been transmitted through the ages. For centuries, medicinal plants were the only resources available for the treatment of several diseases which plagued humanity. In fact, many of today's drugs have been derived from medicinal plants [1].
Additionally, the World Health Organisation has reported that $80 \%$ of the world's population relies on herbal medicine for primary health care [2]. Recently, several ethnobotanical studies have reported the widespread usage of plants for curative purposes among the local Turkish people $[2,4,5]$. However, to the best of our knowledge, several medicinal plants used as folk Turkish medicine have not received scientific attention yet.

In Turkey, the Fabaceae family is the second largest family after Asteraceae and the most economically important family after Poaceae $[6,7]$. Ethnobotanical studies have reported that important taxa from Fabaceae family have been used in folk medicine. For instance, Onobrychis gracilis is commonly used for cold and flu [8]; Vicia faba is used to treat gastrovascular disorders [9]; Vicia cracca subsp. stenophylla is 
used as an anticough agent [10]; Vicia ervilia is used to treat diabetes [11]. In the present investigation, 3 Fabaceae species, namely, Hedysarum varium, Onobrychis hypargyrea, and Vicia truncatula, were evaluated for their possible antioxidant activities and inhibitory action on cholinesterase, tyrosinase, $\alpha$-amylase, and $\alpha$-glucosidase.

\section{Materials and Methods}

2.1. Plant Material and Extraction. Hedysarum varium (Hv) $\left(38^{\circ} 1^{\prime} 49.25^{\prime \prime} \mathrm{N}, 32^{\circ} 30^{\prime} 10.91^{\prime \prime} \mathrm{S}\right)$ was collected from Konya, and Onobrychis hypargyrea (Oh) $\left(40^{\circ} 18^{\prime} 30.00^{\prime \prime} \mathrm{N}, 32^{\circ} 58^{\prime} 39.00^{\prime \prime} \mathrm{S}\right)$ and Vicia truncatula (Vt) $\left(40^{\circ} 27^{\prime} 17.00^{\prime \prime} \mathrm{N}, 32^{\circ} 37^{\prime} 27.00^{\prime \prime} \mathrm{S}\right)$ were collected from Ankara. The plants were identified by Dr. Murad Aydin Sanda, the senior taxonomist of the Department of Biology, Selçuk University, Konya, Turkey, and voucher specimens were deposited at the herbarium of the laboratory. The aerial parts of the plants were dried at room temperature. Air-dried samples (10 g) were macerated in $200 \mathrm{~mL}$ solvent (ethyl acetate (EA), methanol (MeOH), or water $(\mathrm{Aq})$ ) at room temperature for $24 \mathrm{~h}$. The extracts were concentrated under reduced pressure and organic extracts were dissolved in methanol while the aqueous extract was dissolved in water.

\subsection{Quantification of Phenolic Compounds}

2.2.1. Determination of Total Phenol Content. The total phenol content was determined as described by Slinkard and Singleton [12] with slight modifications. Briefly, $0.25 \mathrm{~mL}$ plant extract was mixed with a tenfold diluted Folin-Ciocalteu reagent solution and the mixture was shaken vigorously. After $3 \mathrm{~min}, 0.75 \mathrm{~mL}$ sodium carbonate solution (1\%) was added to the mixture and was allowed to react for $2 \mathrm{~h}$ at room temperature. The absorbance was then read at $760 \mathrm{~nm}$. The total phenol content was expressed as mg gallic acid equivalents (GAE) per g crude extract using a gallic acid standard curve.

2.2.2. Determination of Total Flavonoid Content. The total flavonoid content was determined following the method described by Berk et al. [13]. Briefly, $1 \mathrm{~mL}$ aluminium trichloride $(2 \%)$ solution in methanol was added to $1 \mathrm{~mL}$ plant extract. The absorbance of the mixture was read at $415 \mathrm{~nm}$ after $10 \mathrm{~min}$ incubation at room temperature. The total flavonoid content was expressed as mg rutin equivalents (RE) per g crude extract using a rutin standard curve.

\subsection{Determination of Antioxidant Activities}

2.3.1. Total Antioxidant Capacity (TAC). The reduction of molybdenum(VI) to molybdenum(V) by the plant extracts was used to assess the total antioxidant capacity following the method described by Berk et al. [13] with slight modifications. An aliquot of plant extract $(0.3 \mathrm{~mL})$ was combined with $3 \mathrm{~mL}$ of reagent solution ( $0.6 \mathrm{M}$ sulfuric acid, $28 \mathrm{mM}$ sodium phosphate, and $4 \mathrm{mM}$ ammonium molybdate). The absorbance was read at $695 \mathrm{~nm}$ after $90 \mathrm{~min}$ incubation at $95^{\circ} \mathrm{C} . \mathrm{EC}_{50}$, that is, the effective concentration at which the absorbance was 0.5 , was calculated for the plant extracts and trolox.
2.3.2. $\beta$-Carotene/Linoleic Acid Bleaching Activity. The antilipid peroxidation capacities of the plant extracts were measured by $\beta$-carotene/linoleic acid bleaching [14]. A stock solution of $\beta$-carotene and linoleic acid was prepared from $0.5 \mathrm{mg} \beta$-carotene dissolved in $1 \mathrm{~mL}$ chloroform, $25 \mu \mathrm{L}$ linoleic acid, and $200 \mathrm{mg}$ Tween 40 . The chloroform was completely evaporated using a vacuum evaporator and $100 \mathrm{~mL}$ of oxygenated distilled water was added to the residual mixture. The mixture was shaken vigorously and $1.5 \mathrm{~mL}$ of this mixture was added to $0.5 \mathrm{~mL}$ plant extract and the absorbance at time 0 was measured at $490 \mathrm{~nm}$. The absorbance was monitored at regular intervals, that is, at 30,60, 90, and $120 \mathrm{~min}$. The bleaching rate $(R)$ of $\beta$-carotene was calculated according to

$$
R=\left[\frac{\ln (a / b)}{t}\right]
$$

where $\ln$ represents natural $\log , a$ is the absorbance at time 0 , and $b$ is the absorbance at time $t(30,60,90$, and $120 \mathrm{~min})$. The antioxidant activity (AA) was calculated in terms of percentage inhibition relative to the control from

$$
\mathrm{AA}=\left[\frac{\left(R_{\text {Control }}-R_{\text {Sample }}\right)}{R_{\text {Control }}}\right] \times 100 .
$$

$\mathrm{IC}_{50}$, that is, the concentration of plant extract/trolox required to scavenge $50 \%$ of linoleate, was then determined.

2.3.3. 1,1-Diphenyl-2-picrylhydrazyl (DPPH) Free Radical Scavenging Assay. The effect of the plant extracts on DPPH radical was assessed according to the method described by Sarikurkcu [15]. Briefly, $1 \mathrm{~mL}$ of plant extract was added to $4 \mathrm{~mL}$ DPPH solution (0.004\%) in methanol. The absorbance was measured at $517 \mathrm{~nm}$ after $30 \mathrm{~min}$ incubation at room temperature in the dark. The radical scavenging activity was calculated as follows: \% inhibition $=\left[\left(\mathrm{Abs}_{\text {blank }}-\right.\right.$ $\left.\left.\mathrm{Abs}_{\text {sample }}\right) / \mathrm{Abs}_{\text {blank }}\right] \times 100$, where $\mathrm{Abs}_{\text {blank }}$ is absorbance of the blank and $\mathrm{Abs}_{\text {sample }}$ is absorbance of the sample. Trolox is used as a positive control and $\mathrm{IC}_{50}$ was then determined.

2.3.4. 2,2-Azino-bis(3-ethylbenzothiazoline-6-sulfonic acid) (ABTS) Radical Cation Scavenging Activity. The scavenging activity of the plant extracts on $\mathrm{ABTS}^{\bullet+}$ radical was measured according to the method of Re et al. [16] with slight modifications. $\mathrm{ABTS}^{\circ+}$ radical was produced by reacting $7 \mathrm{mM}$ ABTS solution with $2.45 \mathrm{mM}$ potassium persulfate. The mixture was allowed to stand for 12 to $16 \mathrm{~h}$ in the dark at room temperature. The resulting ABTS solution was diluted with methanol and adjusted to absorbance of $0.700 \pm 0.02$ at $734 \mathrm{~nm}$. Plant extract $(1 \mathrm{~mL})$ was added to ABTS solution $(2 \mathrm{~mL})$ and after $30 \mathrm{~min}$ incubation at room temperature the absorbance was measured at $734 \mathrm{~nm}$. The radical scavenging activity was calculated as follows: $\%$ inhibition $=\left[\left(\mathrm{Abs}_{\text {blank }}-\right.\right.$ $\left.\left.\mathrm{Abs}_{\text {sample }}\right) / \mathrm{Abs}_{\text {blank }}\right] \times 100$, where $\mathrm{Abs}_{\text {blank }}$ is absorbance of the blank and $\mathrm{Abs}_{\text {sample }}$ is absorbance of the sample. Trolox is used as a positive control and $\mathrm{IC}_{50}$ was then calculated.

2.3.5. Cupric Ion Reducing Antioxidant Capacity (CUPRAC) Assay. The cupric ion reducing antioxidant capacity 
(CUPRAC) was determined according to the method described by Apak et al. [17]. Plant extract $(0.5 \mathrm{~mL})$ was added to the reaction mixture containing $10 \mathrm{mM}$ copper chloride $(1 \mathrm{~mL}), 7.5 \mathrm{mM}$ neocuproine $(1 \mathrm{~mL})$, and $1 \mathrm{M}$ ammonium acetate buffer at $\mathrm{pH} 7(1 \mathrm{~mL})$. The absorbance was read at $450 \mathrm{~nm}$ after $30 \mathrm{~min}$ incubation at room temperature. $\mathrm{EC}_{50}$ was determined for each plant extract.

2.3.6. Ferric Reducing Antioxidant Power (FRAP) Assay. The FRAP assay was carried out as described by Aktumsek et al. [18] with slight modifications. Plant extract $(0.1 \mathrm{~mL})$ was added to FRAP reagent solution $(2 \mathrm{~mL})$ containing $0.3 \mathrm{M}$ acetate buffer, pH 3.6, $10 \mathrm{mM}$ 2,4,6-tris(2-pyridyl)-s-triazine (TPTZ) in $40 \mathrm{mM} \mathrm{HCl}$, and $20 \mathrm{mM}$ ferric chloride in a ratio of $10: 1: 1(\mathrm{v} / \mathrm{v} / \mathrm{v})$. The absorbance was then measured at $593 \mathrm{~nm}$ after $30 \mathrm{~min}$ incubation at room temperature. $\mathrm{EC}_{50}$ of the plant extract was then determined.

2.3.7. Metal Chelating Activity on Ferrous Ions. The metal chelating activities of the plant extracts on ferrous ions were determined by the method described by Aktumsek et al. [18]. Briefly, $2 \mathrm{~mL}$ of plant extract was added to $0.05 \mathrm{~mL} 2 \mathrm{mM}$ iron chloride. The reaction was initiated by the addition of $0.2 \mathrm{~mL} 5 \mathrm{mM}$ ferrozine. The absorbance was read at $562 \mathrm{~nm}$ after $10 \mathrm{~min}$ incubation at room temperature. The chelating activity was calculated as follows: $\%$ inhibition $=\left[\left(\mathrm{Abs}_{\mathrm{blank}}-\right.\right.$ $\left.\left.\mathrm{Abs}_{\text {sample }}\right) / \mathrm{Abs}_{\text {blank }}\right] \times 100$, where $\mathrm{Abs}_{\text {blank }}$ is absorbance of the blank and $\mathrm{Abs}_{\text {sample }}$ is absorbance of the sample. EDTA is used as a positive control and $\mathrm{IC}_{50}$ was calculated.

\subsection{Determination of Cholinesterase, Tyrosinase, $\alpha$-Amylase, and $\alpha$-Glucosidase Activity}

2.4.1. Cholinesterase Inhibition Assay. Cholinesterase inhibitory activity was measured using Ellman's method as previously reported by Aktumsek et al. [18] with slight modifications. The plant extract $(50 \mu \mathrm{L})$ was mixed with dithiobisnitro-benzoate (DTNB) $(125 \mu \mathrm{L})$ and cholinesterase solution $(25 \mu \mathrm{L})$ in Tris-HCl buffer $(\mathrm{pH} 8.0)$ in a 96-well microplate. The reaction was initiated by the addition of $25 \mu \mathrm{L}$ of acetylthiocholine iodide or butyrylthiocholine chloride. The absorbance was read at $405 \mathrm{~nm}$ after $10 \mathrm{~min}$ incubation at room temperature. The anticholinesterase activity was calculated as follows: $\%$ inhibition $=\left[\left(\mathrm{Abs}_{\text {blank }}-\right.\right.$ $\left.\mathrm{Abs}_{\text {sample }}\right) / \mathrm{Abs}_{\text {blank }} \mathrm{J} \times 100$, where $\mathrm{Abs}_{\text {blank }}$ is absorbance of the blank and $\mathrm{Abs}_{\text {sample }}$ is absorbance of the sample. Galantamine is used as a positive control and $\mathrm{IC}_{50}$ value was determined.

2.4.2. Tyrosinase Inhibition Assay. Tyrosinase inhibitory activity was measured using the modified dopachrome method previously described by Orhan et al. [19] with slight modifications. Plant extract $(25 \mu \mathrm{L})$ was mixed with tyrosinase solution $(40 \mu \mathrm{L})$ and phosphate buffer $(\mathrm{pH} 6.8)$ $(100 \mu \mathrm{L})$ in a $96-$ well microplate and incubated for $15 \mathrm{~min}$ at $37^{\circ} \mathrm{C}$. L-DOPA $(40 \mu \mathrm{L})$ was then added to the mixture to initiate the reaction. The absorbance was read at $492 \mathrm{~nm}$ after $10 \mathrm{~min}$ incubation at $37^{\circ} \mathrm{C}$. The percentage inhibition of tyrosinase was calculated as follows: \% inhibition = $\left[\left(\mathrm{Abs}_{\text {blank }}-\mathrm{Abs}_{\text {sample }}\right) / \mathrm{Abs}_{\text {blank }}\right] \times 100$, where $\mathrm{Abs}_{\text {blank }}$ is absorbance of the blank and Abs sample is absorbance of the sample. Kojic acid is used as a positive control and $\mathrm{IC}_{50}$ was calculated.

2.4.3. $\alpha$-Amylase Inhibition Assay. $\alpha$-Amylase inhibitory activity was performed using the Caraway-Somogyi iodinepotassium iodide method [20] with some modifications. Briefly, plant extract $(25 \mu \mathrm{L})$ was mixed with $\alpha$-amylase solution $(50 \mu \mathrm{L})$ in phosphate buffer $(\mathrm{pH} 6.9)$ with $6 \mathrm{mM}$ sodium chloride in a 96-well microplate and incubated for $10 \mathrm{~min}$ at $37^{\circ} \mathrm{C}$. The reaction was initiated by the addition of $0.05 \%$ starch solution $(50 \mu \mathrm{L})$. The reaction mixture was incubated for $10 \mathrm{~min}$ at $37^{\circ} \mathrm{C}$. The reaction was then stopped by the addition of $1 \mathrm{M} \mathrm{HCl}(25 \mu \mathrm{L})$, followed by addition of the iodine-potassium iodide solution $(100 \mu \mathrm{L})$. The absorbance was measured at $630 \mathrm{~nm}$. The percentage inhibition of $\alpha$ amylase was calculated as follows: $\%$ inhibition $=\left[\left(\mathrm{Abs}_{\text {blank }}-\right.\right.$ $\left.\left.\mathrm{Abs}_{\text {sample }}\right) / \mathrm{Abs}_{\text {blank }}\right] \times 100$, where $\mathrm{Abs}_{\text {blank }}$ is absorbance of the blank and $\mathrm{Abs}_{\text {sample }}$ is absorbance of the sample. Acarbose is used as a positive control and $\mathrm{IC}_{50}$ was determined.

2.4.4. $\alpha$-Glucosidase Inhibition Assay. $\alpha$-Glucosidase inhibitory activity was performed following the previous method described by Palanisamy et al. [21] with some modifications. Plant extract $(50 \mu \mathrm{L})$ was mixed with glutathione $(50 \mu \mathrm{L}), \alpha$ glucosidase solution $(50 \mu \mathrm{L})$ in phosphate buffer ( $\mathrm{pH} 6.8$ ), and PNPG $(50 \mu \mathrm{L})$ in a 96 -well microplate and incubated for $15 \mathrm{~min}$ at $37^{\circ} \mathrm{C}$. The reaction was stopped by the addition of $0.2 \mathrm{M}$ sodium carbonate $(50 \mu \mathrm{L})$ and the absorbance was read at $400 \mathrm{~nm}$. The percentage inhibition of $\alpha$-glucosidase was calculated as follows: $\%$ inhibition $=\left[\left(\mathrm{Abs}_{\text {blank }}-\right.\right.$ $\left.\left.\mathrm{Abs}_{\text {sample }}\right) / \mathrm{Abs}_{\text {blank }}\right] \times 100$, where $\mathrm{Abs}_{\text {blank }}$ is absorbance of the blank and $\mathrm{Abs}_{\text {sample }}$ is absorbance of the sample. Acarbose is used as a positive control and $\mathrm{IC}_{50}$ was determined.

2.5. Statistical Analysis. The experiments were carried out in triplicate. The results are expressed as mean \pm standard deviation (SD). The differences between the different extracts were analyzed using one-way analysis of variance (ANOVA) followed by Tukey's honestly significant difference post hoc test with $\alpha=0.05$ using SPSS v. 14.0.

\section{Results}

3.1. Quantification of Phenolic Compounds. The total phenol and flavonoid content of the plant extracts are summarised in Table 1. Oh extracts yielded higher phenol content in the following order: OhEA $>\mathrm{OhMeOH}>\mathrm{OhAq}$. On the other hand, it was observed that the flavonoid content of the plant extracts varied in the following order: $\mathrm{MeOH}>\mathrm{Aq}>\mathrm{EA}$. The methanolic and aqueous extracts of $\mathrm{Hv}$ showed the highest flavonoid content.

3.2. Determination of Antioxidant Activities. Table 2 summarises the reducing power and radical scavenging and metal chelating capacities of $\mathrm{Hv}, \mathrm{Oh}$, and Vt extracts. It was found that the plant extracts showed variable radical scavenging capabilities on $\mathrm{DPPH}^{\bullet}$ and $\mathrm{ABTS}^{\circ+}$. Methanolic extracts of $\mathrm{Hv}$ and $\mathrm{Oh}$ and aqueous extract of $\mathrm{Oh}\left(\mathrm{IC}_{50}: 0.30 \pm 0.005\right.$, 
TABLE 1: Total phenol and flavonoid content of the plant extracts.

\begin{tabular}{lcc}
\hline Plant extracts & $\begin{array}{c}\text { Total phenol content } \\
\text { (mg GAE/g extract) }\end{array}$ & $\begin{array}{c}\text { Total flavonoid content } \\
\text { (mg RE/g extract) }\end{array}$ \\
\hline HvEA & $20.96 \pm 1.291$ & $2.41 \pm 0.205$ \\
HvMeOH & $45.11 \pm 1.399$ & $39.71 \pm 0.092$ \\
HvAq & $37.97 \pm 1.033$ & $34.53 \pm 2.001$ \\
\hline OhEA & $83.25 \pm 0.914$ & $9.92 \pm 0.030$ \\
OhMeOH & $73.20 \pm 0.756$ & $27.00 \pm 0.544$ \\
OhAq & $69.38 \pm 0.992$ & $25.20 \pm 0.088$ \\
\hline VtEA & $27.19 \pm 1.283$ & $1.45 \pm 0.200$ \\
VtMeOH & $20.90 \pm 0.190$ & $22.45 \pm 0.325$ \\
VtAq & $25.86 \pm 0.085$ & $8.67 \pm 0.109$ \\
\hline
\end{tabular}

Hv: Hedysarum varium; Oh: Onobrychis hypargyrea; Vt: Vicia truncatula; EA: ethyl acetate extract; $\mathrm{MeOH}$ : methanolic extract; Aq: aqueous extract.

$0.29 \pm 0.002$, and $0.27 \pm 0.001 \mathrm{mg} / \mathrm{mL}$, resp.) significantly $(P<0.05)$ scavenged $\mathrm{DPPH}^{\circ}$ as compared to the positive control trolox $\left(\mathrm{IC}_{50}: 0.31 \pm 0.003 \mathrm{mg} / \mathrm{mL}\right)$. On the other hand, it was observed that the plant extracts scavenged $\mathrm{ABTS}^{\circ+}$ but were significantly $(P<0.05)$ less active than trolox $\left(\mathrm{IC}_{50}\right.$ : $0.18 \pm 0.004 \mathrm{mg} / \mathrm{mL}$ ). Likewise, the plant extracts showed low chelating activity on ferrous ions. Ethyl acetate extracts of $\mathrm{Hv}$ and $\mathrm{Vt}\left(\mathrm{IC}_{50}: 1.07 \pm 0.006\right.$ and $1.05 \pm 0.001 \mathrm{mg} / \mathrm{mL}$, resp. $)$ showed potent $\beta$-carotene bleaching capacities as compared to trolox $\left(\mathrm{IC}_{50}: 1.10 \pm 0.004 \mathrm{mg} / \mathrm{mL}\right)$. Additionally, it was noted that the plant extracts exhibited variable reducing potential. However, as shown in Table 2, none of the plant extracts exhibited reducing activity which was significantly $(P<0.05)$ lower than trolox.

It was observed that the plant extracts exhibited variable inhibitory effects on cholinesterases (acetyl cholinesterase and butyryl cholinesterase), tyrosinase, $\alpha$-amylase, and $\alpha$ glucosidase (Table 3 ). The plant extracts were significantly $(P<0.05)$ less active than the positive controls galantamine, kojic acid, and acarbose against cholinesterases, tyrosinase, and $\alpha$-amylase, respectively. However, Hv extracts $\left(\mathrm{IC}_{50}: 3.77 \pm 0.016,2.88 \pm 0.051\right.$, and $5.18 \pm 0.078 \mathrm{mg} / \mathrm{mL}$ for ethyl acetate, methanolic, and aqueous extract, resp.), methanolic and aqueous extracts of $\mathrm{Oh}\left(\mathrm{IC}_{50}: 3.89 \pm 0.097\right.$ and $5.86 \pm 0.050 \mathrm{mg} / \mathrm{mL}$, resp.), and ethyl acetate extract of Vt $\left(\mathrm{IC}_{50}: 2.74 \pm 0.044 \mathrm{mg} / \mathrm{mL}\right)$ significantly $(P<0.05)$ inhibited $\alpha$-glucosidase as compared to acarbose $\left(\mathrm{IC}_{50}: 6.67 \pm\right.$ $0.200 \mathrm{mg} / \mathrm{mL}$ ).

\section{Discussion}

The use of plant-based products for the management and treatment of diseases is gaining much momentum from both scientific and consumer perspectives. Indeed, herbal therapies have been used for curative purposes since the dawn of civilisation. The relentless efforts for wellbeing and to combat diseases have guided scientists as well as health care providers towards safer and natural alternatives such as medicinal plants. Currently, there is a renewed interest in natural inhibitors from plant-based medicines to modulate physiological effects of enzymes linked to several pathologies such as diabetes, obesity, neurodegenerative diseases, and inflammation, amongst others. The present study has endeavoured to investigate the possible inhibitory effects of three medicinal plants to modulate key enzymes involved in diabetes $(\alpha$ amylase and $\alpha$-glucosidase), neurodegenerative disorders (tyrosinase, acetylcholinesterase, and butyrylcholinesterase), and melanogenesis (tyrosinase).

Diabetes is a chronic disease characterised by elevated blood sugar level which leads to the onset of serious health complications such as cardiovascular problems, nephropathy, and neuropathy [22]. The inhibition of $\alpha$-amylase and $\alpha$ glucosidase which are involved in the hydrolysis of sugars in vivo has been an important strategy for the management of diabetes thereby lowering postprandial glucose level. Inhibitors of $\alpha$-glucosidase delay the breaking down of carbohydrate in the gut and decrease postprandial blood glucose peak in diabetic patients. Synthetic oral hypoglycaemic agents such as acarbose, miglitol, and voglibose are currently used for the treatment of diabetes [23]. However, their side effects, such as abdominal discomforts and flatulence, have guided research towards safer and more effective alternatives notably from natural sources [24]. In the present study, the plant extracts showed inhibition against both $\alpha$ amylase and $\alpha$-glucosidase. Additionally, it was noted that the plant extracts were potent inhibitors of $\alpha$-glucosidase and the methanolic and aqueous extracts of $\mathrm{Hv}$ and $\mathrm{Oh}$ showed significantly lower $\mathrm{IC}_{50}$ values than acarbose and therefore can be potentially useful as an effective therapy for postprandial hyperglycemia with minimal side effects. This is in line with report of Picot et al. [25] who reported natural $\alpha$ glucosidase inhibitors from plants to have strong inhibition towards the activity of the enzyme compared to acarbose.

Plant extracts from the present study were found to inhibit acetylcholinesterase although their inhibitory action was less potent than the known inhibitor galantamine. It was also found that some of the plant extracts showed inhibition against another cholinesterase enzyme, butyrylcholinesterase. Inhibition of cholinesterases, the key enzymes in the breakdown of acetylcholine, is considered one of the treatment strategies against several neurological disorders. The inhibition of cholinesterases leads to an increase in the concentration of acetylcholine in the brain which subsequently results in an increase in communication between the brain nerve cells $[22,26]$. Indeed, both acetylcholinesterase and butyrylcholinesterase inhibitors have been key targets for the treatment of neurodegenerative disorders such as Alzheimer's disease [27, 28]. Cholinesterase inhibitors constitute, to date, the most effective approach to treat the cognitive symptoms of neurological disorders. Hence, plants studied in the present study can be of therapeutic utility both on cognitive performances and on the quality of life in these patients.

Tyrosinase is a key enzyme responsible for the hydroxylation of tyrosine to L-DOPA and its subsequent oxidation to dopaquinone [29]. Dopaquinone and its derivatives produced via the biosynthesis of melanin by tyrosinase are thought to play a pivotal role in the degeneration of nigrostriatal dopaminergic neurons in Parkinson's disease [30]. Tyrosinase inhibitors have attracted much interest due 


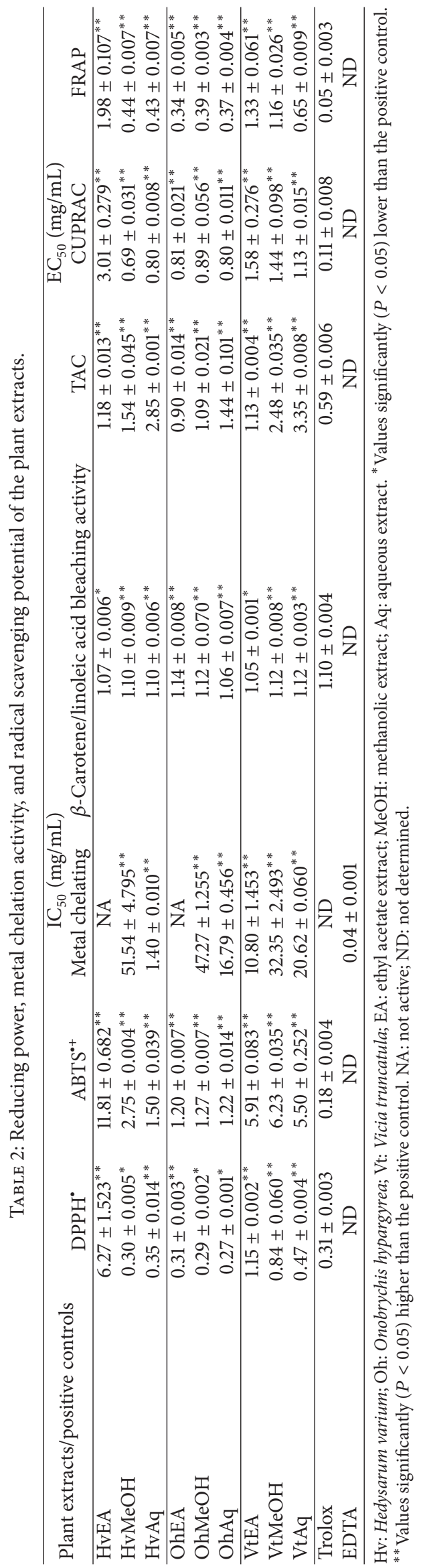


TABLE 3: Inhibition concentration of the plant extracts on cholinesterases, tyrosinase, $\alpha$-amylase, and $\alpha$-glucosidase.

\begin{tabular}{|c|c|c|c|c|c|}
\hline \multirow{3}{*}{ Plant extracts/positive controls } & \multicolumn{5}{|c|}{$\mathrm{IC}_{50}(\mathrm{mg} / \mathrm{mL})$} \\
\hline & \multicolumn{2}{|c|}{ Cholinesterases } & \multirow{2}{*}{ Tyrosinase } & \multirow{2}{*}{$\alpha$-Amylase } & \multirow{2}{*}{$\alpha$-Glucosidase } \\
\hline & Acetylcholinesterase & Butyrylcholinesterase & & & \\
\hline HvEA & $1.44 \pm 0.001^{* *}$ & $3.29 \pm 0.018^{* *}$ & $2.63 \pm 0.035^{* *}$ & $3.65 \pm 0.188^{* *}$ & $3.77 \pm 0.016^{*}$ \\
\hline $\mathrm{HvMeOH}$ & $1.50 \pm 0.044^{* *}$ & NA & $2.50 \pm 0.014^{* *}$ & $5.59 \pm 0.191^{* *}$ & $2.88 \pm 0.051^{*}$ \\
\hline $\mathrm{HvAq}$ & $9.22 \pm 0.527^{* *}$ & NA & $3.46 \pm 0.012^{* *}$ & $13.39 \pm 0.219^{* *}$ & $5.18 \pm 0.078^{*}$ \\
\hline OhEA & $1.46 \pm 0.016^{* *}$ & $3.81 \pm 0.252^{* *}$ & $4.30 \pm 0.057^{* *}$ & $4.92 \pm 0.335^{* *}$ & $20.95 \pm 0.581^{* *}$ \\
\hline $\mathrm{OhMeOH}$ & $1.63 \pm 0.018^{* *}$ & NA & $3.50 \pm 0.069^{* *}$ & $5.51 \pm 0.141^{* *}$ & $3.89 \pm 0.097^{*}$ \\
\hline OhAq & $4.46 \pm 0.024^{* *}$ & NA & $21.76 \pm 1.357^{* *}$ & $11.84 \pm 0.465^{* *}$ & $5.86 \pm 0.050^{*}$ \\
\hline VtEA & $1.57 \pm 0.003^{* *}$ & $3.15 \pm 0.052^{* *}$ & $3.21 \pm 0.012^{* *}$ & $2.07 \pm 0.095^{* *}$ & $2.74 \pm 0.044^{*}$ \\
\hline VtMEOH & $1.60 \pm 0.008^{* *}$ & NA & $2.26 \pm 0.010^{* *}$ & $4.21 \pm 0.180^{* *}$ & $8.68 \pm 0.214^{* *}$ \\
\hline VtAq & $5.55 \pm 0.080^{* *}$ & NA & $4.41 \pm 0.145^{* *}$ & $13.74 \pm 0.514^{* *}$ & $8.31 \pm 0.355^{* *}$ \\
\hline Galantamine & $0.002 \pm 0.000$ & $0.002 \pm 0.001$ & ND & ND & ND \\
\hline Kojic acid & ND & ND & $0.14 \pm 0.001$ & ND & ND \\
\hline Acarbose & $\mathrm{ND}$ & ND & ND & $1.00 \pm 0.023$ & $6.67 \pm 0.200$ \\
\hline
\end{tabular}

Hv: Hedysarum varium; Oh: Onobrychis hypargyrea; Vt: Vicia truncatula; EA: ethyl acetate extract; MeOH: methanolic extract; Aq: aqueous extract. ${ }^{*}$ Values significantly $(P<0.05)$ lower than the positive control. ${ }^{* *}$ Values significantly $(P<0.05)$ higher than the positive control.

to the key role of tyrosinase in mammalian melanogenesis [31]. Inhibitors of the tyrosinase enzyme, such as kojic acid (by-product in the fermentation of malting rice, produced naturally by several species of fungi such as Aspergillus oryzae), azelaic acid (isolated from wheat, rye, and barley and produced naturally by Malassezia furfur), and arbutin (extracted from bearberry plants), have been utilised in the pharmaceutical and cosmetic industry for their potential of thwarting the excessive production of melanin. However, controversies still persist in the literature concerning their safety and efficacy $[31,32]$. Interestingly, plant extracts evaluated in the present study were found to inhibit tyrosinase activity but at higher concentration than the known inhibitor kojic acid.

The variation in activity of the plant extracts against these enzymes might be explained based on the complex composition and potential synergistic effect(s) of individual phytochemicals present in each sample. Interestingly, we found varying concentration of phenolics and flavonoids in extracts of these plants. Previously, it has been reported that inhibitory activity of plant extracts might be due to the presence of several phytochemicals such as flavonoids, saponins, and tannins. Additionally, studies on $\alpha$-amylase and $\alpha$-glucosidase inhibitors isolated from medicinal plants suggest that several potential inhibitors belong to flavonoid class which has features of inhibiting metabolic enzymes. Recently, it has been shown that phenolics play a role in mediating amylase inhibition and therefore have potential to contribute to the management of type 2 diabetes [33].

Free radicals are known to play a pivotal role in the onset and exacerbation of several pathologies [34]. By counteracting these free radicals, antioxidants help in preserving good health. Indeed, phytochemicals have received much interest owing to their molecular structure which consists of hydroxyl groups on aromatic rings and this has been associated with their functionality as oxidant scavengers [35]. Phytochemicals act by inhibiting oxidative chain reactions at cellular level thereby increasing their therapeutic efficacy [36]. In the present study, the phenolic content of the plant extracts was estimated using the Folin-Ciocalteau method. This method is rapid and simple but also measures various interfering nonphenolic compounds such as ascorbic acid, thiol, and nitrogen containing compounds [37]. Flavonoids are the major class of phenolic compounds and are known to exhibit strong antioxidant activities [38, 39]. Interestingly, in the present study, it was observed that Oh extract showed high phenolic and flavonoid content.

Various assays were employed to study the antioxidant potential of the extracts of $\mathrm{Hv}, \mathrm{Oh}$, and $\mathrm{Vt}$. The gross antioxidant capacities of the plant extracts were determined using two methods, namely, the TAC and $\beta$-carotene bleaching assays. The TAC assay is based on the reduction of $\mathrm{Mo}(\mathrm{IV})$ to $\mathrm{Mo}(\mathrm{V})$ by antioxidants and the formation of green phosphate/Mo(V) compound [36]. On the other hand, the ability of the plant extracts to scavenge linoleate-derived free radicals and thus prevent $\beta$-carotene bleaching was also investigated [40]. It was observed that $\mathrm{Oh}$ extracts actively reduced $\mathrm{Mo}(\mathrm{IV})$ to $\mathrm{Mo}(\mathrm{V})$ but their $\mathrm{EC}_{50}$ values were significantly higher than the standard trolox. It was also noted that ethyl acetate extracts showed $\mathrm{IC}_{50}$ significantly lower than trolox for the $\beta$-carotene bleaching assay. This was associated with the "polar paradox theory" which suggests that nonpolar antioxidants are more effective in relatively nonpolar systems [24]. The high phenolic and flavonoid content of Oh were linked to the observed gross antioxidant capacity.

The reducing power of plant extracts is regarded as an indication of their antioxidant capacities [41]. FRAP and CUPRAC were used to assess the reductive potentials of the plant extracts. The plant extracts exerted variable reducing potentials thereby suggesting that phenolic compounds acted as reductones. Reductones are thought to exert antioxidant action by donating a hydrogen atom thus breaking the chain reaction [42]. Additionally, it was reported that reductones 
react with peroxide precursors thereby preventing peroxide formation [43].

The free radical quenching potential of the plant extracts was determined using two nitrogen-centered radicals, namely, $\mathrm{DPPH}^{\bullet}$ and $\mathrm{ABTS}^{\bullet+}$. $\mathrm{DPPH}^{\bullet}$ is a stable dark purple free radical which turns into a yellow stable diamagnetic molecule upon reaction with antioxidants [44]. On the other hand, $\mathrm{ABTS}^{\circ+}$ is a blue radical cation which is converted into a colourless form in the presence of a hydrogen donor [42]. Results from the present study have demonstrated that the plant extracts showed good abilities to quench both $\mathrm{DPPH}^{\circ}$ and $\mathrm{ABTS}^{\circ+}$. The ability of the plant extracts to quench $\mathrm{DPPH}^{\bullet}$ and $\mathrm{ABTS}^{\bullet+}$ was related to the observed high phenol content.

One of the most important mechanisms of action of antioxidants involves the chelation of prooxidant metals such as iron. Iron promotes oxidation by acting as catalyst of free radical chain reactions [45]. The chelation of iron by phytochemicals decreases its prooxidant effect through the stabilisation of its oxidised form [40]. Indeed, the plant extracts were found to chelate iron but were less potent than EDTA.

\section{Conclusion}

Data gathered from the present investigation demonstrated that $\mathrm{Hv}, \mathrm{Oh}$, and $\mathrm{Vt}$ possessed antioxidant capabilities and also exhibited inhibitory potential against cholinesterase, tyrosinase, $\alpha$-amylase, and $\alpha$-glucosidase in vitro. Furthermore, to date, no such scientific information on these plants has been gathered. However, it was observed that the antioxidant capacities and $\alpha$-amylase, cholinesterase, and tyrosinase inhibitory activities of the plant extracts were less potent than the controls. Thus, it might be argued that the plants possessed moderate antioxidant and enzyme inhibitory properties. Further studies are needed for the identification of bioactive constituents for the determination of molecular mechanisms involved in antioxidant and enzymatic activities of these plant extracts.

\section{Conflict of Interests}

The authors declare that there is no conflict of interests regarding the publication of this paper.

\section{Acknowledgment}

This research was supported by the Scientific and Technological Research Council of Turkey (TUBITAK) (Project no. 113Z892).

\section{References}

[1] E. Özdemir and K. Alpınar, "An ethnobotanical survey of medicinal plants in western part of central Taurus Mountains: Aladaglar (Nigde-Turkey)," Journal of Ethnopharmacology, vol. 166, pp. 53-65, 2015.

[2] B. Güler, E. Manav, and E. Uğurlu, "Medicinal plants used by traditional healers in Bozüyük (Bilecik-Turkey)," Journal of Ethnopharmacology, vol. 173, pp. 39-47, 2015.
[3] M. Mükemre, L. Behçet, and U. Çakılcıoğlu, "Ethnobotanical study on medicinal plants in villages of Çatak (Van-Turkey)," Journal of Ethnopharmacology, vol. 166, pp. 361-374, 2015.

[4] S. A. Sargin, "Ethnobotanical survey of medicinal plants in Bozyazı district of Mersin, Turkey," Journal of Ethnopharmacology, vol. 173, pp. 105-126, 2015.

[5] M. Y. Paksoy, S. Selvi, and A. Savran, "Ethnopharmacological survey of medicinal plants in Ulukışla (Niğde-Turkey)," Journal of Herbal Medicine, 2015.

[6] D. F. Chamberlain, "Glycyrrhiza," in Flora of Turkey and the East Aegean 364 Islands, P. H. Davis, Ed., pp. 260-263, Edinburgh University Press, Edinburgh, UK, 1970.

[7] P. H. Davis, R. R. Mill, and K. Tan, Flora of Turkey and the East Aegean Islands, vol. 10, supplement 1, Edinburgh University Press, Edinburgh, UK, 1988.

[8] S. Demirci and N. Özhatay, "An ethnobotanical study in Kahramanmaraş (Turkey); wild plants used for medicinal purpose in Andirin, Kahramanmaraş," Turkish Journal of Pharmaceutical Sciences, vol. 9, no. 1, pp. 75-92, 2012.

[9] S. A. Sargin, E. Akçicek, and S. Selvi, "An ethnobotanical study of medicinal plants used by the local people of Alaşehir (Manisa) in Turkey," Journal of Ethnopharmacology, vol. 150, no. 3, pp. 860-874, 2013.

[10] S. Hayta, R. Polat, and S. Selvi, "Traditional uses of medicinal plants in ElazIğ (Turkey)," Journal of Ethnopharmacology, vol. 154, no. 3, pp. 613-623, 2014.

[11] E. Yeşilada, G. Honda, E. Sezik et al., "Traditional medicine in Turkey. V. Folk medicine in the inner Taurus Mountains," Journal of Ethnopharmacology, vol. 46, no. 3, pp. 133-152, 1995.

[12] K. Slinkard and V. L. Singleton, "Total phenol analyses: automation and comparison with manual methods," American Journal of Enology and Viticulture, vol. 28, pp. 49-55, 1977.

[13] S. Berk, B. Tepe, S. Arslan, and C. Sarikurkcu, "Screening of the antioxidant, antimicrobial and DNA damage protection potentials of the aqueous extract of Asplenium ceterach DC," African Journal of Biotechnology, vol. 10, no. 44, pp. 8902-8908, 2011.

[14] C. Sarikurkcu, F. Eryigit, M. Cengiz, B. Tepe, A. Cakir, and E. Mete, "Screening of the antioxidant activity of the essential oil and methanol extract of Mentha pulegium L. from Turkey," Spectroscopy Letters, vol. 45, no. 5, pp. 352-358, 2012.

[15] C. Sarikurkcu, "Antioxidant activities of solvent extracts from endemic Cyclamen mirabile Hildebr. tubers and leaves," African Journal of Biotechnology, vol. 10, no. 5, pp. 831-839, 2011.

[16] R. Re, N. Pellegrini, A. Proteggente, A. Pannala, M. Yang, and C. Rice-Evans, "Antioxidant activity applying an improved ABTS radical cation decolorization assay," Free Radical Biology and Medicine, vol. 26, no. 9-10, pp. 1231-1237, 1999.

[17] R. Apak, K. Güçlü, M. Özyürek, S. Esin Karademir, and E. Erçağ, "The cupric ion reducing antioxidant capacity and polyphenolic content of some herbal teas," International Journal of Food Sciences and Nutrition, vol. 57, no. 5-6, pp. 292-304, 2006.

[18] A. Aktumsek, G. Zengin, G. O. Guler, Y. S. Cakmak, and A. Duran, "Antioxidant potentials and anticholinesterase activities of methanolic and aqueous extracts of three endemic Centaurea L. species," Food and Chemical Toxicology, vol. 55, pp. 290-296, 2013.

[19] I. E. Orhan, F. S. Senol, A. R. Gulpinar, N. Sekeroglu, M. Kartal, and B. Sener, "Neuroprotective potential of some terebinth coffee brands and the unprocessed fruits of Pistacia terebinthus L. and their fatty and essential oil analyses," Food Chemistry, vol. 130, no. 4, pp. 882-888, 2012. 
[20] X.-W. Yang, M.-Z. Huang, Y.-S. Jin, L.-N. Sun, Y. Song, and H.S. Chen, "Phenolics from Bidens bipinnata and their amylase inhibitory properties," Fitoterapia, vol. 83, no. 7, pp. 1169-1175, 2012.

[21] U. D. Palanisamy, L. T. Ling, T. Manaharan, and D. Appleton, "Rapid isolation of geraniin from Nephelium lappaceum rind waste and its anti-hyperglycemic activity," Food Chemistry, vol. 127, no. 1, pp. 21-27, 2011.

[22] A. Abirami, G. Nagarani, and P. Siddhuraju, "In vitro antioxidant, anti-diabetic, cholinesterase and tyrosinase inhibitory potential of fresh juice from Citrus hystrix and C. maxima fruits," Food Science and Human Wellness, vol. 3, no. 1, pp. 16-25, 2014.

[23] S. Gurudeeban, K. Satyavani, and T. Ramanathan, "Alpha glucosidase inhibitory effect and enzyme kinetics of coastal medicinal plants," Bangladesh Journal of Pharmacology, vol. 7, no. 3, pp. 186-191, 2012.

[24] G. Zengin, C. Sarikurkcu, A. Aktumsek, and R. Ceylan, "Sideritis galatica Bornm.: a source of multifunctional agents for the management of oxidative damage, Alzheimer's's and diabetes mellitus," Journal of Functional Foods, vol. 11, pp. 538-547, 2014.

[25] C. M. N. Picot, A. H. Subratty, and M. F. Mahomoodally, "Inhibitory potential of five traditionally used native antidiabetic medicinal plants on $\alpha$-amylase, $\alpha$-glucosidase, glucose entrapment, and amylolysis kinetics in vitro," Advances in Pharmacological Sciences, vol. 2014, Article ID 739834, 7 pages, 2014.

[26] J. S. Choi, M. N. Islam, M. Y. Ali, E. J. Kim, Y. M. Kim, and H. A. Jung, "Effects of C-glycosylation on anti-diabetic, anti-Alzheimer's disease and anti-inflammatory potential of apigenin," Food and Chemical Toxicology, vol. 64, pp. 27-33, 2014.

[27] J. K. R. da Silva, L. C. Pinto, R. M. R. Burbano et al., "Essential oils of Amazon Piper species and their cytotoxic, antifungal, antioxidant and anti-cholinesterase activities," Industrial Crops and Products, vol. 58, pp. 55-60, 2014.

[28] F. S. Senol, I. E. Orhan, and O. Ustun, "In vitro cholinesterase inhibitory and antioxidant effect of selected coniferous tree species," Asian Pacific Journal of Tropical Medicine, vol. 8, no. 4, pp. 269-275, 2015.

[29] D. D. Orhan, F. S. Senol, S. Hosbas, and I. E. Orhan, "Assessment of cholinesterase and tyrosinase inhibitory and antioxidant properties of Viscum album L. samples collected from different host plants and its two principal substances," Industrial Crops and Products, vol. 62, pp. 341-349, 2014.

[30] T. Hasegawa, "Tyrosinase-expressing neuronal cell line as in vitro model of Parkinson's disease," International Journal of Molecular Sciences, vol. 11, no. 3, pp. 1082-1089, 2010.

[31] T.-S. Chang, "An updated review of tyrosinase inhibitors," International Journal of Molecular Sciences, vol. 10, no. 6, pp. 2440-2475, 2009.

[32] S. Parvez, M. Kang, H.-S. Chung et al., "Survey and mechanism of skin depigmenting and lightening agents," Phytotherapy Research, vol. 20, no. 11, pp. 921-934, 2006.

[33] M. I. Kazeem, J. O. Adamson, and I. A. Ogunwande, "Modes of inhibition of $\alpha$-amylase and $\alpha$-glucosidase by aqueous extract of morinda lucida benth leaf," BioMed Research International, vol. 2013, Article ID 527570, 6 pages, 2013.

[34] N. Demir, O. Yildiz, M. Alpaslan, and A. A. Hayaloglu, "Evaluation of volatiles, phenolic compounds and antioxidant activities of rose hip (Rosa L.) fruits in Turkey," LWT_Food Science and Technology, vol. 57, no. 1, pp. 126-133, 2014.
[35] A. B. Tukun, N. Shaheen, C. P. Banu, M. Mohiduzzaman, S. Islam, and M. Begum, "Antioxidant capacity and total phenolic contents in hydrophilic extracts of selected Bangladeshi medicinal plants," Asian Pacific Journal of Tropical Medicine, vol. 7, no. 1, pp. S568-S573, 2014.

[36] N. Akhtar, Ihsan-ul-Haq, and B. Mirza, "Phytochemical analysis and comprehensive evaluation of antimicrobial and antioxidant properties of 61 medicinal plant species," Arabian Journal of Chemistry, 2015.

[37] H. H. Doğan, "Evaluation of phenolic compounds, antioxidant activities and fatty acid composition of Amanita ovoidea (Bull.) Link. in Turkey," Journal of Food Composition and Analysis, vol. 31, no. 1, pp. 87-93, 2013.

[38] K. Robards, P. D. Prenzler, G. Tucker, P. Swatsitang, and W. Glover, "Phenolic compounds and their role in oxidative processes in fruits," Food Chemistry, vol. 66, no. 4, pp. 401-436, 1999.

[39] J.-H. Xie, C.-J. Dong, S.-P. Nie et al., "Extraction, chemical composition and antioxidant activity of flavonoids from Cyclocarya paliurus (Batal.) Iljinskaja leaves," Food Chemistry, vol. 186, pp. 97-105, 2015.

[40] M. Z. Končić, M. Barbarić, I. Perković, and B. Zorc, "Antiradical, chelating and antioxidant activities of hydroxamic acids and hydroxyureas," Molecules, vol. 16, no. 8, pp. 6232-6242, 2011.

[41] M. B. Gholivand, M. Piryaei, and S. M. Maassoumi, "Antioxidant activity of Ziziphora tenuoir methanolic extracts and comparison of the essential oil in two stages of growth," Chinese Journal of Natural Medicines, vol. 12, no. 7, pp. 505-511, 2014.

[42] R. S. Kumar, B. Rajkapoor, and P. Perumal, "Antioxidant activities of Indigofera cassioides Rottl. Ex. DC. using various in vitro assay models," Asian Pacific Journal of Tropical Biomedicine, vol. 2, no. 4, pp. 256-261, 2012.

[43] I. Geckil, B. Ates, G. Durmaz, S. Erdogan, and I. Yilmaz, "Antioxidant, free radicalscavenging and metal characteristics of propolis," American Journal of Biochemistry and Biotechnology, vol. 1, pp. 27-31, 2005.

[44] U. I. Alhaji, N. U. Samuel, M. Aminu et al., "In vitro antitrypanosomal activity, antioxidant property and phytochemical constituents of aqueous extracts of nine Nigerian medicinal plants," Asian Pacific Journal of Tropical Disease, vol. 4, no. 5, pp. 348-355, 2014.

[45] T. M. Chaouche, F. Haddouchi, R. Ksouri, and F. Atik-Bekkara, "Evaluation of antioxidant activity of hydromethanolic extracts of some medicinal species from South Algeria," Journal of the Chinese Medical Association, vol. 77, no. 6, pp. 302-307, 2014. 

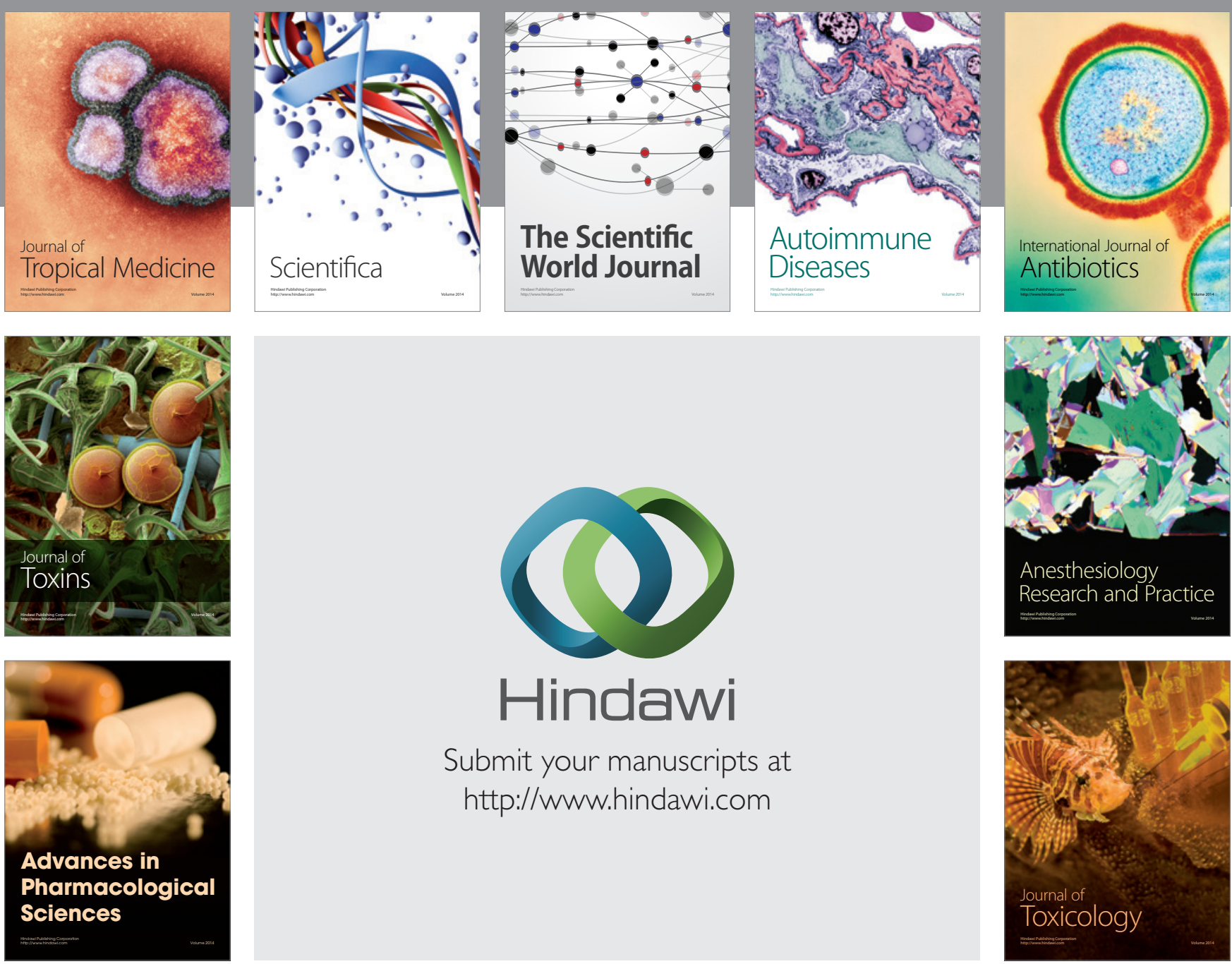

\section{Hindawi}

Submit your manuscripts at

http://www.hindawi.com
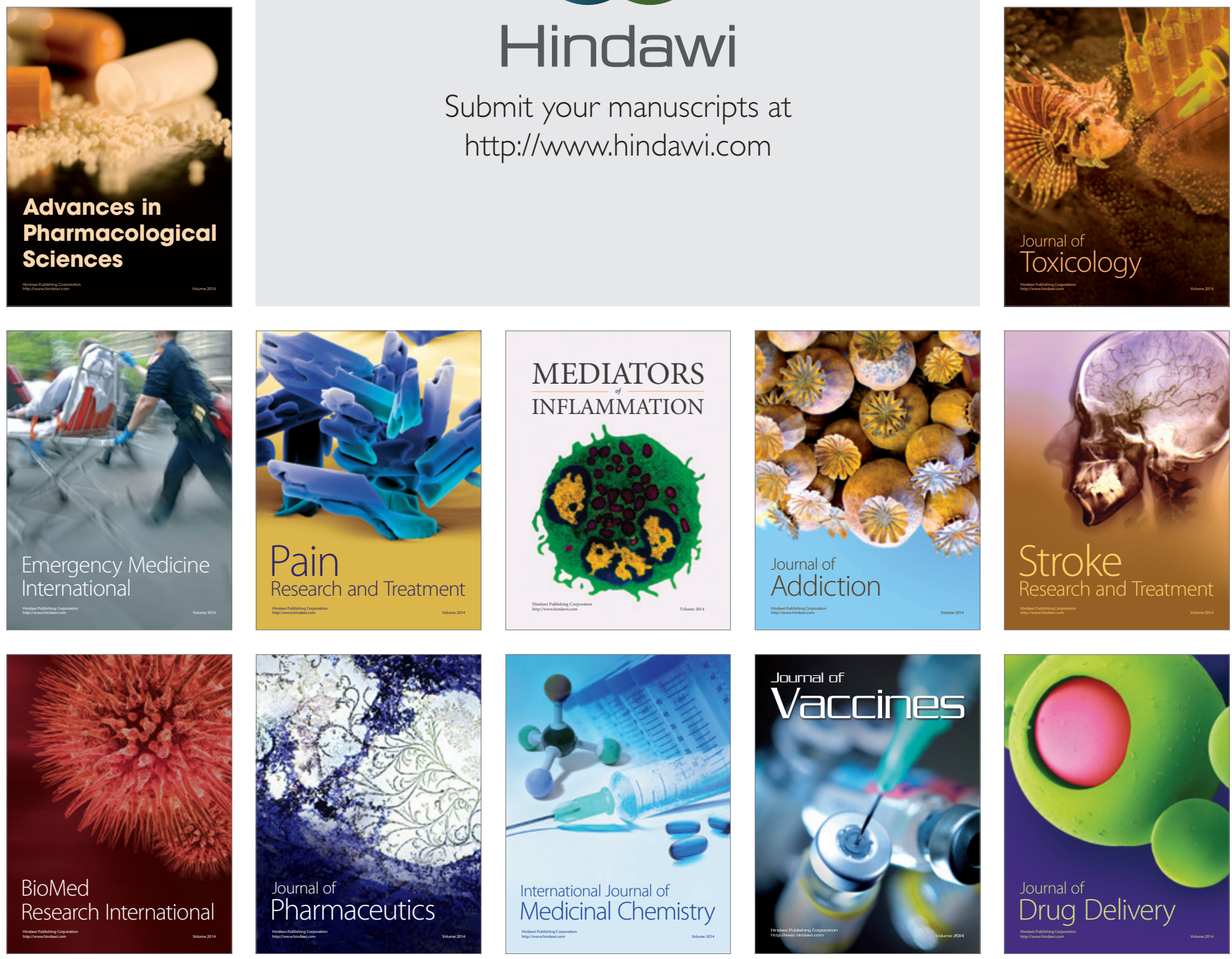